\title{
Effect of capsule addition and healing temperature on the self-healing potential of asphalt mixtures
}

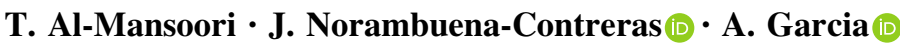

Received: 6 October 2017 / Accepted: 10 March 2018/Published online: 26 March 2018

(C) The Author(s) 2018

\begin{abstract}
This paper presents the self-healing results of asphalt mixtures by the action of capsules containing sunflower oil as encapsulated rejuvenator. Three different capsule contents, $0.10,0.25$ and $0.50 \%$ by total weight of the mixture, were added to the samples. The mechanical and thermal properties of capsules have been evaluated. In addition, the effect of the capsule addition and the healing temperature on the self-healing properties of asphalt mixtures have been evaluated through three-point bending tests on the cracked asphalt beams with, and without, capsules. The test was implemented by comparing the strength recovery of the broken beams after healing to their original flexural strength. It was proven that the capsules can resist the mixing and compaction processes and break inside the asphalt mixture as a result of applying external mechanical loads, releasing the encapsulated oil. The capsules content in asphalt mixture has a significant influence on the healing level, where a higher capsule content led to obtaining higher healing levels. Likewise, asphalt with, and
\end{abstract}

T. Al-Mansoori · J. Norambuena-Contreras .

A. Garcia $(\bowtie)$

Nottingham Transportation Engineering Centre, School of Civil Engineering, University of Nottingham, University Park, Nottingham, UK

e-mail: alvaro.garcia@nottinghmam.ac.uk

J. Norambuena-Contreras

LabMAT, Department of Civil and Environmental

Engineering, University of Bío-Bío, Concepción, Chile without, capsules presents an increase of the healing level when the temperature increases. Finally, it was proved that healing temperature has higher influence on the healing levels of the asphalt below $40{ }^{\circ} \mathrm{C}$.

Keywords Asphalt mixture - Capsule influence · Encapsulated rejuvenator - Healing temperature · Healing level

\section{Introduction}

Asphalt mixture is a heterogeneous and time-dependant material, which is becoming the most famous material used to build road pavements. It generally consists of aggregates, mastic, and spaces of air voids. Asphalt pavements are usually designed for a service life of 15-30 years. The load carrying capacity of asphalt pavements is related to the bond at aggregatemastic level. Mastic is considered the softer part of the asphalt mixture that constitutes from mixing the asphalt binder with fine aggregate and filler. With time, the binding material (bitumen) ages and becomes brittle and less adhesive, making the asphalt pavement stiffer and less flexible [1,2]. Cracks and distresses will start to appear and external maintenance is usually required every 8 years by replacing the damaged top layers with new asphalt layers or by overlaying [3]. Recycling can be one of the cost- 
effective pavement repair methods, although there is still an important issue in dealing with large quantities of aged bitumen [4]. Therefore, using rejuvenators, such as sunflower oil, to restore and renovate asphalt original properties via a self-healing process is the most promising technique to pavement maintenance in a low-cost and environmentally friendly solution.

Self-healing is defined as the ability of the material to repair itself when subjected to mechanically or thermally induced damages, and it could be activated naturally or by external stimuli, which accelerate and trigger the self-healing, such as heat [5-8]. For example, a tree can heal its damaged trunk naturally by itself, and human skin, as another example, can stop the bleeding and heals itself naturally when suffering a small cut or injury [9]. Bitumen is well known for being a self-healing material due to its potential to recover strength and stiffness by closing the cracks that appear on the asphalt pavement during repeated traffic loads or temperature drop [10]. Viscosity and surface energy are highly influential on bitumen selfhealing [11-14], as lower viscosity leads to lower stiffness, which may increase the healing level of the asphalt mixture. The self-healing capability of asphalt decreases or disappears with time leading to asphalt pavement failure, including surface ravelling and reflective cracking [15].

The natural self-healing of asphalt pavement requires undergoing higher temperatures and enough rest periods, which are practically difficult to achieve due to the continuous traffic load and changing temperature [16]. Based on that, some maintenance techniques have been studied to trigger the healing and increase its speed and adequacy. Some of these techniques, which have been proven in the laboratory, are the induction [17] and microwave heating [18]. In these techniques, asphalt mixtures containing metallic additives are exposed to alternating electromagnetic fields of variable frequency to promote the flow of bitumen into the cracks [19]. When induction and microwave, techniques have been used in the laboratory, cracked asphalt beams have been able to recover up to 80 , and $90 \%$, of their mechanical strength, respectively [18]. Another technique to accelerate asphalt self-healing is the use of capsules containing rejuvenators. When external damage happens to the pavement, cracks break the capsules leading them to release the rejuvenator into the bitumen, which will diffuse and reduce the bitumen viscosity so that it can easily flow into the cracks [20].

So far, two different methods are known for producing capsules containing rejuvenator that can be used to accelerate asphalt self-healing: (1) Microcapsules of size less than $100 \mu \mathrm{m}$, which consist of oil droplets covered by a polymeric shell [4, 21, 22]; and (2) Capsules of sizes greater than $100 \mu \mathrm{m}$. Microcapsules have been proven to release their rejuvenator content in the presence of cracks but have not been tested to resist asphalt mixing and compaction [4, 23]. Furthermore, the healing of cracks in the presence of this type of capsule has been tested for bitumen only, not for asphalt mixture [24]. The other type of capsules are either of a porous sand core [25] or polymeric [26]. The healing agent used in this type of capsule is sunflower cooking oil because of its availability, safety, and ability to rejuvenate bitumen [27]. All these types are proven to release the healing agent in the asphalt mixture when cracked, and successfully resisted asphalt mixing and compaction [25, 26, 28]. The mechanical properties of asphalt mixture including rutting, stiffness modulus and particle loss, have been tested in the presence of this type of capsule and the results show that these capsules affect positively the asphalt pavement performance [31]. The healing ability of the capsules in Micaelo et al. [26] was evaluated in the laboratory by using computer tomography scans (CT-scans) and the results show visualised healing where all cracks have vanished after specified healing time.

The aim of this paper is to evaluate the effect of the capsule addition and the healing temperature on the self-healing potential of asphalt mixtures. With this purpose, an extensive experimental programme was carried out to measure the (1) thermal and mechanical properties of capsules containing sunflower oil, and (2) the crack-healing properties of asphalt mixture at different temperatures and healing times. Asphalt healing properties have been evaluated through measuring strength recovery by three-point bending (3 PB) tests on the cracked asphalt mixture samples with, and without, capsules. This test reports the flexural strength recovery of the asphalt beams after healing and its proportion to their original strength. Finally, all the methodologies and results of these analyses are presented and discussed in the sections of this paper. 


\section{Materials and test methods}

\subsection{Asphalt mixture and polymeric capsules}

A dense asphalt mixture AC 20 base (EN 13108-1) and polymeric capsules were used in this study. Asphalt mixture consists of virgin bitumen $40 / 60$ pen with a density of $1.030 \mathrm{~g} / \mathrm{cm}^{3}$ and a softening point of $49.8{ }^{\circ} \mathrm{C}$ and graded Tunstead limestone aggregate with a density of $2.700 \mathrm{~g} / \mathrm{cm}^{3}$. Table 1 presents the aggregates gradation and design properties of the asphalt mixture used. Furthermore, capsules were made of a calcium-alginate polymer that encapsulated the healing agent. The healing agent used in the capsules was a commercial sunflower oil. Its smoke point is $227{ }^{\circ} \mathrm{C}$, while the flash point is $315^{\circ} \mathrm{C}$. This type of oil was selected because of the low cost and the fact that extra health and safety procedures are not required for handling in the laboratory [27]. The polymer structure of the capsules is made of sodium alginate $\left(\mathrm{C}_{6} \mathrm{H}_{7} \mathrm{O}_{6} \mathrm{Na}\right)$, which is an anionic polysaccharide widely distributed in the cell walls of brown algae; and a calcium source, provided by SigmaAldrich as anhydrous, granular pellets of calcium chloride $\left(\mathrm{CaCl}_{2}\right)$, of $7 \mathrm{~mm}$ diameter, and $93 \%$ purity.

Table 1 Design properties of asphalt mixture AC 20 base $40 / 60$

\begin{tabular}{ll}
\hline Aggregates gradation $(\mathrm{mm})$ & \% passing \\
\hline 20 & 100.0 \\
10 & 80.2 \\
6.3 & 60.3 \\
4 & 45.3 \\
2 & 29.7 \\
0.5 & 15.5 \\
0.125 & 9.9 \\
0.063 & 8.0 \\
\hline Property & Value \\
\hline Binder content $(\% \mathrm{M})$ & 4.5 \\
Bulk density $\left(\mathrm{kg} / \mathrm{m}^{3}\right)$ & 2384 \\
Air voids $(\%)$ & 4.5 \\
Voids in mineral aggregate $(\%)$ & 14.9 \\
Voids filled with bitumen $(\%)$ & 69.8 \\
\hline
\end{tabular}

2.2 Encapsulation procedure of capsules

Capsules of average diameter $2.9 \mathrm{~mm}$ were fabricated at $20^{\circ} \mathrm{C}$ by ionotropic gelation of alginate in the presence of calcium, as it is defined in Micaelo et al. [26] and shown in Fig. 1a and their internal structure presented in Fig. 1b. To prepare the polymeric capsules, $50 \mathrm{~g}$ of oil were added to $550 \mathrm{~g}$ of water and stirred to produce an emulsion. Oil and water were mixed using a laboratory gear drive mixer for $1 \mathrm{~min}$ at $400 \mathrm{rpm}$. Then, the sodium alginate was added and stirred until its complete dissolution at $400 \mathrm{rpm}$ for $10 \mathrm{~min}$. The amount of the sodium alginate used to produce the capsules was $15 \mathrm{~g}$, since lower amounts could not form capsules because the structure of the calcium-alginate (shown in Fig. 1b) was not strong enough to hold the oil, and higher values produced too strong capsules, with a high polymer to oil proportion. At the same time, a calcium chloride solution was prepared by dissolving $12 \mathrm{~g}$ of calcium chloride in $600 \mathrm{ml}$ of water $\left(\mathrm{CaCl}_{2}\right.$ at solution $\left.2 \%\right)$. Capsules were formed by letting the oil-in-water emulsion drop into the calcium chloride solution from a $1000 \mathrm{ml}$ pressure-equalizing dropping funnel with $3 \mathrm{~mm}$ socket size. The process is called a cross-link of calcium-alginate via a chemical process known as ionotropic gelation of sodium alginate in the presence of calcium ions [29]. During the capsule formation process, the calcium-chloride solution was gently agitated using a magnetic stirrer at $60 \mathrm{rpm}$. Capsules were allowed to stay in the solution until the end of the encapsulation process. Then, the capsules were washed with deionized water and dried in an electric dryer at $40{ }^{\circ} \mathrm{C}$ for $12 \mathrm{~h}$. Finally, the capsules were stored in a freezer to avoid any possibility of release and oxidation of the sunflower oil at room temperature.

\subsection{Manufacturing of asphalt mixture samples}

Asphalt mixture beams with and without capsules were manufactured in this study. In asphalt mixture with capsules, three different capsules contents as a percentage of the total mixture were used, $0.1,0.25$ and $0.5 \%$. These contents provide an approximate oilto-bitumen content by mass in bitumen of 1.1, 2.8 and $5.5 \%$, respectively. These values were not exceeding (6-8\%), which is the maximum sunflower oil content in bitumen to be used as a rejuvenator [30]. In a 

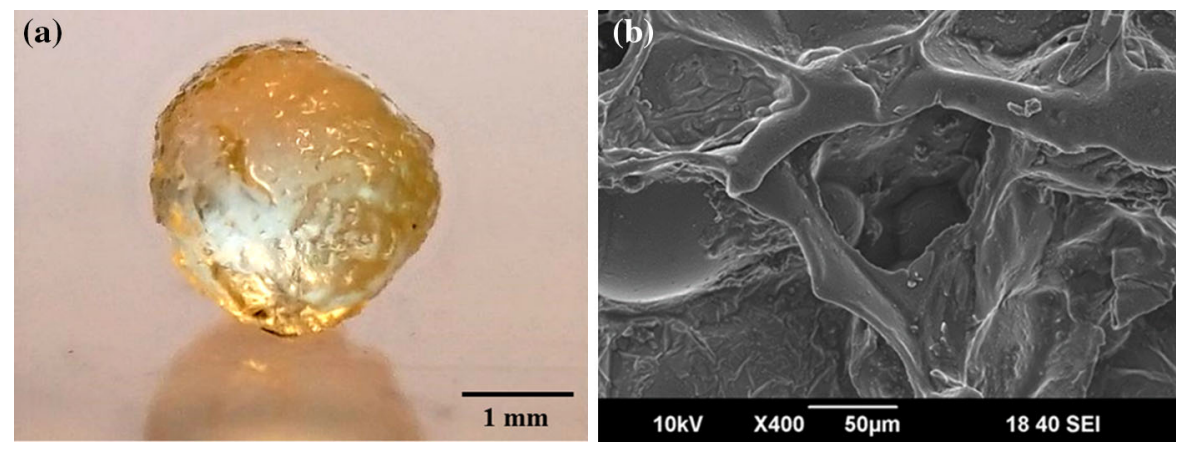

Fig. 1 a Spherical capsule produced in this study. b Scanning electron microscopy (SEM) image of the internal structure of capsule

previous research, Micaelo et al. [26] concluded that this type of capsule can release oil to the asphalt mixture during the mixing and compaction process. Therefore, an equivalent amount of sunflower oil was added to the asphalt mixture without capsules to differentiate the healing caused by the capsules from that caused by the oil released during the manufacturing process. It was assumed that the oil released during mixing and compaction was uniformly dispersed in the asphalt mixture as they are considered as a part of aggregate during mixing. Asphalt mixture was produced in the laboratory in batches of approximately $14 \mathrm{~kg}$, using a lab mixer equipped with a helical horizontal mixing shaft. The aggregates and bitumen were pre-heated at $160{ }^{\circ} \mathrm{C}$ for 12 and $4 \mathrm{~h}$, respectively, while the capsules were left to defrost for $2 \mathrm{~h}$ at $20^{\circ} \mathrm{C}$ before mixing. All these materials were mixed for $2 \mathrm{~min}$ at $125 \mathrm{rpm}$ at $160{ }^{\circ} \mathrm{C}$, ensuring an adequate dispersion. Then, capsules or oil were added to the drum and mixed for $20 \mathrm{~s}$ to obtain a uniform dispersion of them. Then, the mixture was poured into the moulds for compaction by using a roller slab compactor to produce an asphalt slab with dimensions of $306 \times 306 \times 60 \mathrm{~mm}$. The slabs were compacted to the design air voids, see Table 1 . The samples used were asphalt mixture beams cut from the produced slabs where each slab is cut into six identical asphalt beams of $150 \times 100 \times 60 \mathrm{~mm}$, see Fig. 2. Likewise, to facilitate the creation of a single crack surface during crack-healing tests, a transverse notch of $5 \times 5 \mathrm{~mm}$ was carved at the mid-point, on the bottom surface of the beams. Finally, a total of 360 asphalt mixture beams with, and without, capsules were manufactured in this study.

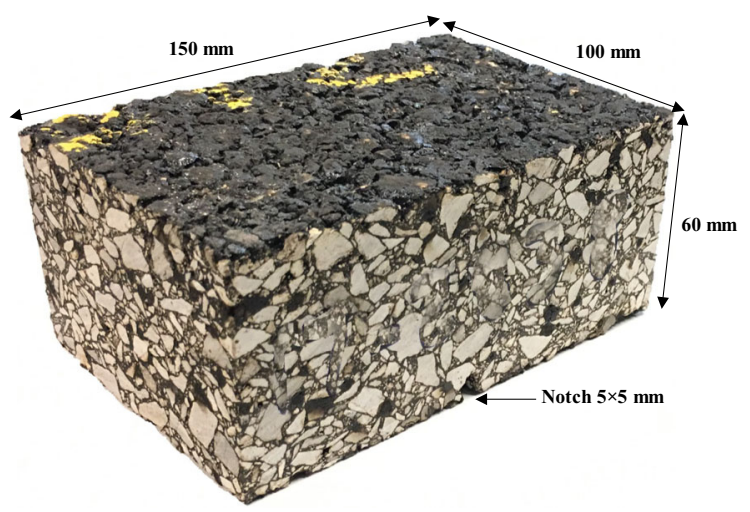

Fig. 2 The asphalt mixture beam used in the crack-healing tests

\subsection{Compressive strength of capsules}

The mechanical strength of capsules was measured through uniaxial compression tests on a total of 10 capsules. Capsules were loaded until failure, at a loading rate of $0.2 \mathrm{~mm} / \mathrm{min}$. The tests were performed at temperatures of 20 and $130{ }^{\circ} \mathrm{C}$, using an Instron equipment Model 5969 with a $5 \mathrm{kN}$ load cell and environmental chamber with temperature control.

\subsection{Thermal stability of capsules}

The composition and thermal resistance of capsules and their individual components were evaluated by means of Thermogravimetric Analysis (TGA). The tests were performed on a NETZSCH TG 449 F3 Jupiter Thermo-Microbalance, using nitrogen atmosphere and a heating rate of $10{ }^{\circ} \mathrm{C} / \mathrm{min}$. TGA profiles were recorded in a temperature range of $0-1000{ }^{\circ} \mathrm{C}$. Finally, aluminium crucibles were used for sample measurements. 


\subsection{Self-healing asphalt measurements}

To evaluate the self-healing properties of asphalt with capsules under conditions similar to that in the field, a novel experimental crack-healing methodology was used [31]. Self-healing of asphalt mixtures was quantified as the healing level reached from the flexural strength recovery of cracked asphalt mixture beams tested under a three-point bending ( $3 \mathrm{~PB}$ ) test after a defined healing time. The crack-healing test was implemented according to the following steps (see Fig. 3):

- Step A. Asphalt mixture beams, with and without capsules, were conditioned at $-20{ }^{\circ} \mathrm{C}$ for a minimum of $4 \mathrm{~h}$ and then, a $3 \mathrm{~PB}$ test was carried out on the asphalt mixture beam at a loading rate of $2 \mathrm{~mm} / \mathrm{min}$ until the beam was broken in two pieces.

- Step B. After the 3 PB test, a thin plastic membrane, able to adapt its shape to the faces of the crack, is placed between the two broken pieces of the asphalt beam. This is to prevent oil from capsules to diffuse to both sides of the crack at time $0 \mathrm{~h}$, which could affect the accuracy of selfhealing results at different healing times. Then, the two pieces of the broken beam are put back together and introduced into a steel mould. To break the capsules, the beam inside the steel mould must be defrozen by placing it in a temperature controlled chamber at $20{ }^{\circ} \mathrm{C}$ for $2 \mathrm{~h}$ and later a compressive load is uniformly applied on the top surface of the beams, at a loading rate of $2 \mathrm{~mm} /$ min, until the vertical deformation reached is $5 \mathrm{~mm}$. This vertical deformation breaks the capsules to release their content inside the asphalt beam. Later, the broken beam is taken out of the mould and the plastic sheet is removed, then the two pieces of the beam are put together again in the steel mould.

- Step C. To begin the healing of the broken beam, the asphalt beam in the steel mould was placed into a temperature-controlled chamber at $20{ }^{\circ} \mathrm{C}$ for a defined healing time, ranging from 6 to $192 \mathrm{~h}$ (0.3-8 days). Once the healing time was reached, the healed beam was removed from the chamber and steel mould, and Step A was repeated thus completing a damage-healing cycle.

The healing level, $H L$, reached for each cracked asphalt mixture beam after a specific healing time was defined as the relationship between the maximum load of the beam initially tested, $F_{o}$, and the maximum load measured in the same beam after the healing process, $F_{t}$ :

$H L=\frac{F_{t}}{F_{o}}$

Finally, with the aim of evaluating the temperature influence on the efficiency of the self-healing process

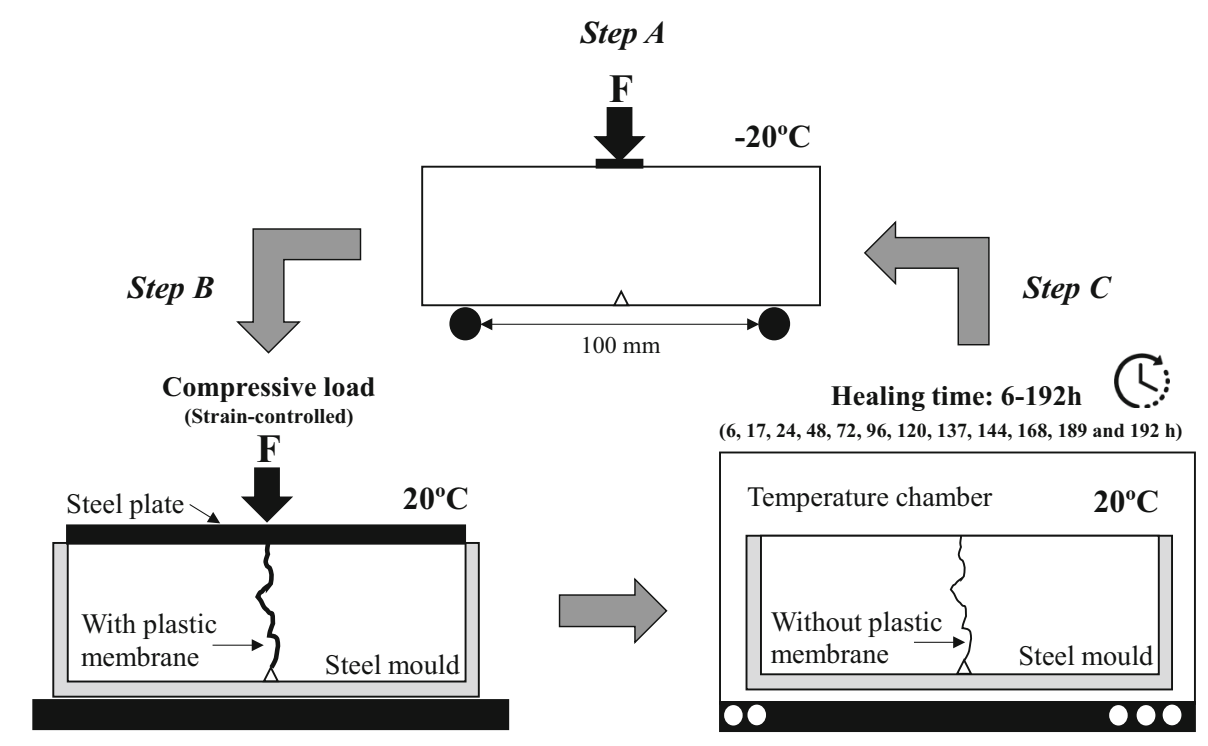

Fig. 3 Schematic diagram of the crack-healing test for asphalt mixtures with capsules (based on Ref. [31] 
of the asphalt with, and without, capsules, crackhealing measurements were also carried out on the asphalt mixture beams, with $0.5 \%$ of capsules, at eight different healing temperatures $(-5,5,10,15,20,30$, 40, and $50{ }^{\circ} \mathrm{C}$ ), see Step C in Fig. 3.

\subsection{Quantification of oil release from capsules}

The release of the oil from the capsules into the asphalt mixture was chemically analysed by using Fourier Transform Infrared Spectroscopy (FTIR) spectrum model Bruker Tensor 27. Samples were taken from the asphalt mixture beams with capsules after $72 \mathrm{~h}$ of healing time. Moreover, oil was added to some asphalt samples, this amount represents $100 \%$ of oil release (full breakage of the capsules). Based on this, the percentage of oil release in asphalt samples with capsules are calculated and quantified accordingly. Samples for this test were taken to cover the lens of the FTIR equipment, which are about $2 \mathrm{~mm}$ in diameter and $1 \mathrm{~mm}$ height. Three to five samples were repeated for each case, depending on their consistency.

These oil contents were added as a percentage of the total amount of bitumen content with respect to the capsule percentage used in each asphalt mixture, and they were 1.1, 2.8 and $5.5 \%$ for asphalt mixtures with capsule content of $0.1,0.25$ and $0.5 \%$, respectively. Samples for asphalt mixture beams without capsules were also tested to compare the results. The test was set in the absorption mode, in the range of 400 to $4000 \mathrm{~cm}^{-1}$, with a resolution of $4 \mathrm{~cm}^{-1}$ and the effect of sunflower oil in bitumen was evaluated from changes in the absorption peak between the wavenumbers 1700 and $1800 \mathrm{~cm}^{-1}$. This range was adopted to determine the amount of oil in the asphalt mixture. Vegetable oils have a distinct peak at $\sim 1745 \mathrm{~cm}^{-1}$ (C-O stretch) while the bitumen has zero index in this range [30]. The curves were normalised in the selected wavelength range and the area under the curve was measured using the trapezoidal rule of numerical integration [32].

\subsection{Thermal expansion of asphalt}

Thermal expansion measurements of asphalt samples at different temperatures, ranging from 5 to $50{ }^{\circ} \mathrm{C}$, were developed by means of a Thermomechanical Analyser (TMA) equipment model Q400. The thermal expansion test was applied to asphalt samples to measure the change of dimensions of the asphalt when heated, while the sample is simultaneously subjected to mechanical loading. The tests were conducted at a heating rate of $5{ }^{\circ} \mathrm{C} / \mathrm{min}$ for asphalt samples with, and without, oil. The percentage of oil added to the asphalt samples was as that released from capsules inside the asphalt mixture after full breakage, and the highest content of capsules $(0.50 \%$ by total weight of the mixture) was considered. Samples with dimensions $5 \times 5 \times 10 \mathrm{~mm}$ were placed in a conditioned chamber and the temperature was changed in steps. Finally, all sensors and LVDTs were previously calibrated and connected to a computer to provide a continuous record of the length with every temperature change.

\subsection{Viscosity test of bitumen}

The viscosity test was performed by means of a Dynamic Shear Rheometer (DSR) supplied by Malvern Instruments Ltd. The bitumen samples were tested with, and without, oil at eight different temperatures $-5,5,10,15,20,30,40$ and $50{ }^{\circ} \mathrm{C}$ with oscillatory sweep frequency of $0.1-10 \mathrm{~Hz}$. The same oil percentage considered in the thermal expansion tests was used in the viscosity test for samples with oil. A two parallel-plate geometry was used: $8 \mathrm{~mm}$ diameter for test temperatures of -5 to $40{ }^{\circ} \mathrm{C}$, and $25 \mathrm{~mm}$ diameter for the temperature of $40-50{ }^{\circ} \mathrm{C}$. A gap of $2 \mathrm{~mm}$ between the spindle and the sample was used to minimise the effect of rubber particles on the viscoelastic measurements.

\section{Results and discussion}

\subsection{Characterisation of capsules}

Capsule characteristics investigation is crucial to evaluate their feasibility as healing agents for asphalt pavement. The size distribution and composition of these capsules is presented in [33]. In this way, two main characteristics of the capsules were presented in this study: mechanical strength and thermal susceptibility of the calcium-alginate capsules. The capsules mechanical strength were tested at two different temperatures, namely, 20 and $130{ }^{\circ} \mathrm{C}$. These test temperatures were aimed at representing capsules conditions at ambient temperature and during asphalt mixture fabrication and in-service. For the highest 
temperature condition it was important to be above $100{ }^{\circ} \mathrm{C}$. Testing at higher than $130{ }^{\circ} \mathrm{C}$, for example $150{ }^{\circ} \mathrm{C}$ or more, was not possible due to the equipment used. In Fig. 4a, the average results of load-displacement curves of the capsules broken by compression at these two temperatures, 20 and $130{ }^{\circ} \mathrm{C}$ are presented. It can be observed that capsules presented a limited stiffness depending on the test temperature used. In general, capsules showed a ductile behaviour and the peak load was reached at deformation levels between 0.3 and $0.5 \mathrm{~mm}$. For the curve of the capsule tested at $130{ }^{\circ} \mathrm{C}$, it can be seen that there are some small pumps on the curve before the rupture. This reason for that could be the movement of oil inside the capsule, due to higher temperature. The amount of deformation capsules undergo before rupture is called the deformation level, represented in ( $\mathrm{mm})$. This deformation level measured at $130{ }^{\circ} \mathrm{C}$ is reduced to almost half the value of that measured at $20^{\circ} \mathrm{C}$, which proves that the compressive strength of the capsules is highly affected by the test temperature. However, Garcia et al. [25] proved that the minimum strength necessary to resist the mixing and compaction process for capsules of similar size to those in this research was $10 \mathrm{~N}$. Therefore, based on the results obtained in this study, the capsules tested can resist the asphalt mixing and compaction process.

Furthermore, the TGA results for the capsules studied in this paper are presented in Fig. 4b. From this figure, it can be observed that the material's mass changed with the temperature, starting with a small mass loss of about $5 \%$ at $200{ }^{\circ} \mathrm{C}$. However, at temperatures higher than $500{ }^{\circ} \mathrm{C}$, the capsules lost approximately $90 \%$ of their mass. This result could be related to the mass loss of the oil and the polymer with the temperature individually. Likewise, Fig. $4 \mathrm{~b}$ shows the TGA results of the individual components used for the encapsulation process: calcium-alginate polymer and sunflower oil.

In Fig. $4 \mathrm{~b}$ it can be observed that calcium-alginate polymer loses about $6 \%$ of mass before $200{ }^{\circ} \mathrm{C}$ and $39 \%$ up to $400{ }^{\circ} \mathrm{C}$. Afterwards, there is a fast decrease of mass until $1000{ }^{\circ} \mathrm{C}$, when only $9.5 \%$ of the total mass of calcium-alginate remains. However, the healing agent (sunflower oil) does not lose mass before $200{ }^{\circ} \mathrm{C}$ and it loses about $21 \%$ of the mass up to $400{ }^{\circ} \mathrm{C}$. Additionally, between $300{ }^{\circ} \mathrm{C}$ and $490{ }^{\circ} \mathrm{C}$ there is a fast decrease of mass and, afterwards, only a small mass loss can be observed. The remaining mass after TGA analysis was $7.0 \%$. From these results, it can be concluded that the polymeric capsules suffered only a minor mass loss $(\leq 5 \%)$ in the temperature range used for the production of hot mix asphalt $\left(\sim 160{ }^{\circ} \mathrm{C}\right)$, which was mainly caused by the effect of degradation of the polymer and water evaporation.

\subsection{Influence of capsules content on the healing properties}

Figure 5 presents self-healing results of asphalt beams containing different percentages of capsules $(0.1,0.25$ and $0.50 \%$ by total weight of the mixture) and tested at a healing temperature of $20^{\circ} \mathrm{C}$. Figure 5 a shows the healing levels results reached for all the asphalt mixture beams, with, and without, capsules, at different healing times ranging from 6 to $192 \mathrm{~h}$. In this figure, it can be observed that the healing levels in the asphalt beams with capsules were higher than in
Fig. 4 Capsule characteristics for a mechanical strength, and b temperature susceptibility
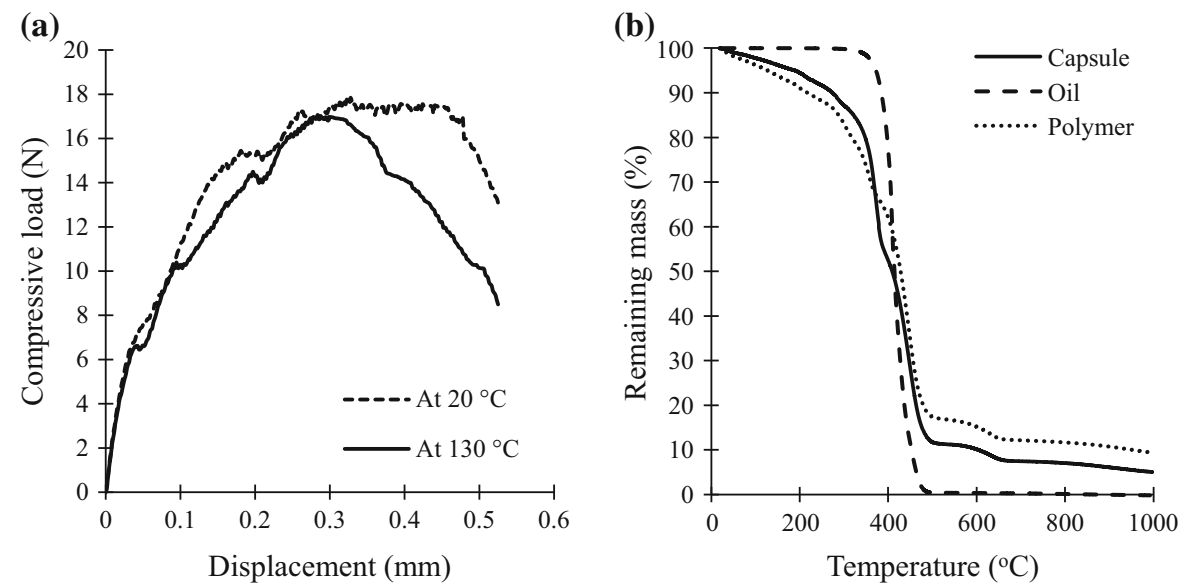
(a)

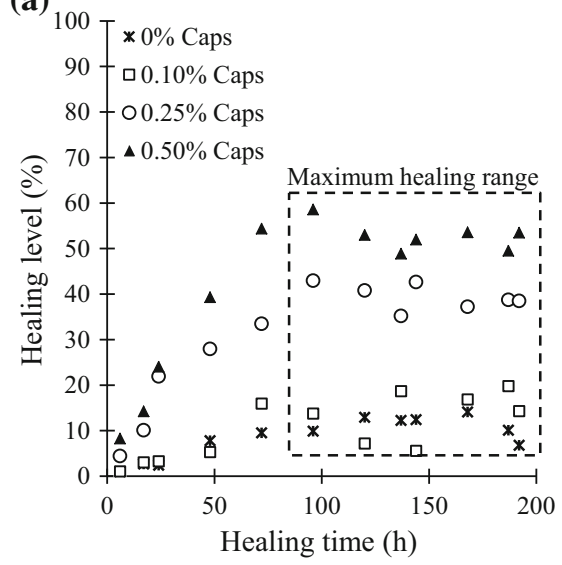

(b)

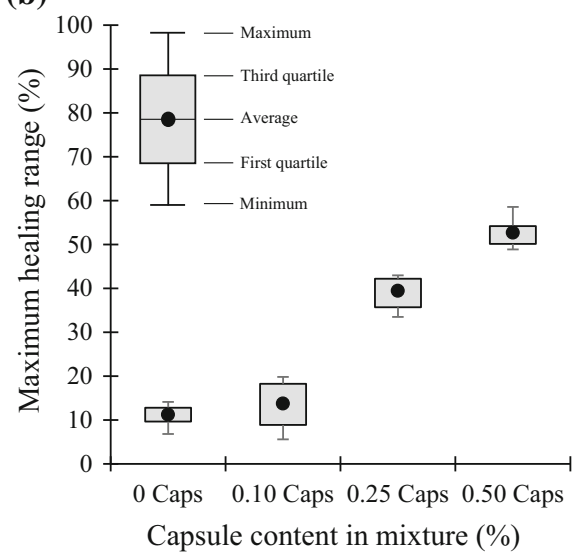

Fig. 5 Self-healing results for asphalt mixture samples with and without capsules: a healing level depending on healing time, and $\mathbf{b}$ box plots of the maximum healing range (96-196 h) with capsule content in the mixture

beams without capsules and that the healing level of asphalt mixtures with and without capsules increased with the healing time until a maximum value, and then remained constant. Based on the results, maximum healing level value was reached, which is, the value that healing level stops increasing until the end of the test. In general, the healing level at $96 \mathrm{~h}$ is the highest value that can be reached and remained mostly constant until 192 h, see the box in Fig. 5a.

The healing level curve start to be constant after a certain healing time, namely after $96 \mathrm{~h}$ until the end of the test. The average healing level obtained from these healing times is called the maximum healing range. Results reached in the maximum healing level are shown in box plots in Fig. 5b: 13.75, 39.44 and $52.72 \%$ for asphalt mixtures with capsule content of $0.10,0.25$ and $0.50 \%$, respectively. Likewise, asphalt mixtures without capsules $(\mathrm{WO} / \mathrm{C})$ presented an average maximum healing level of $11.22 \%$. These results prove that a higher capsule content in the mixture resulted in higher healing levels for all the healing times studied. This conclusion is reasonable due to the fact that a higher capsule content increases the probability of breaking more capsules when the mixture is subjected to external damage, which increases the potential released oil content in the mixture [31]. To prove this, Fig. 6 presents the results for the quantity of broken capsules as a percentage of the total capsules used for asphalt mixtures with different capsule content and tested at healing temperature of $20{ }^{\circ} \mathrm{C}$. The results of broken capsules were represented before, and after, the external

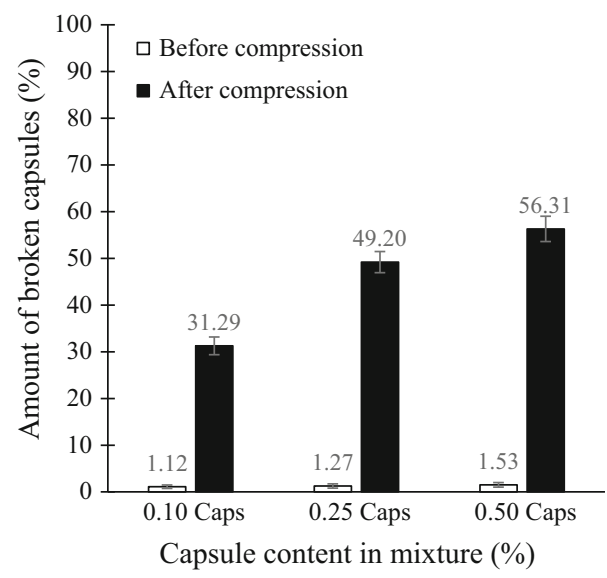

Fig. 6 Amount of broken capsules for asphalt mixtures with different capsule content in mixture

compression load applied to the samples in the laboratory as described in Sect. 2.6 (Step B). From Fig. 6 it can be observed that asphalt mixtures with the highest capsule content, $0.50 \%$, presents the highest percentage of broken capsules after the compression loading of $56.31 \%$ of the total amount of the capsules in the mixture, compared to 49.20 and $31.29 \%$ of mixtures with capsules contents of 0.25 and $0.10 \%$, respectively.

Moreover, Fig. 5b presents the maximum healing range that can be obtained from asphalt mixtures with three different capsule contents compared to a mixture without capsules. Apparently, the healing range is dependent on the capsules content in the mixture, where a higher capsule content presents the higher 
healing range obtained. However, the healing range of the asphalt mixture without capsules was similar to that of mixtures with $0.10 \%$ capsule content, see Fig. 5b. In fact, these asphalt mixtures without capsules were treated with some oil during the mixing process. The amount of oil added to these mixtures was similar to the amount of oil released from damaged capsules during mixing and compaction process because of mixing temperature or compaction loads.

Figure 6 presents the quantity of broken capsules before compression, which means during mixing and compaction processes. These amounts were evaluated as $0.1,0.2$ and $0.5 \mathrm{~g}$ from mixtures with capsule content of $0.1,0.25$ and $0.50 \%$, respectively. So, the reason for adding these amounts of oil to mixtures without capsules is to exclude the effect of this released oil from self-healing evaluations and keep it restricted to the oil released from capsules after applying compressive loads to damage the capsules in the mixture. The amount of oil added to the mixture without capsules in Fig. $5 \mathrm{~b}$ was $0.5 \mathrm{~g}$, which was similar to the oil released from asphalt mixtures with $0.50 \%$ of capsule content.

\subsection{Influence of temperature on the healing properties}

Figure 7 shows the results of healing level for all asphalt mixture beams without capsules (Fig. 7a) and with capsules (Fig. 7b), tested at eight different healing temperatures $(-5,5,10,15,20,30,40$ and $50{ }^{\circ} \mathrm{C}$ ) in the healing times range from 6 to $192 \mathrm{~h}$. The capsules content used in this test was $0.50 \%$ of the total weight of the asphalt mixture. Similar to Fig. 5b, the results from Fig. 7 show that the healing level of asphalt mixtures increased with the time until a maximum value where it remained constant. In general, this maximum healing level was reached after approximately $96 \mathrm{~h}$ and remained approximately constant until the end of the test for both mixtures with, and without, capsules. Evidently, this behaviour depends on the healing temperature and the quantity of broken capsules in the asphalt beams after compressive load. Figure 8 shows the quantity of capsules broken by external compressive loads at different temperatures. In this figure, it can be observed that the stiffer the asphalt samples the fewer the broken capsules, and that the percentage of broken capsules increased with temperature as mixtures become less viscous. Therefore, in less stiff asphalt samples tested at $-5{ }^{\circ} \mathrm{C}$ the broken capsules were $10.39 \%$ of the total capsules in the mixture, while in asphalt samples tested at $50{ }^{\circ} \mathrm{C}$ the percentage of broken capsules reached $60.47 \%$.

Furthermore, from Fig. 7 it can be noticed that tests performed at $30{ }^{\circ} \mathrm{C}$ or below show higher healing levels for asphalt samples with capsules than those without capsules, except at $-5{ }^{\circ} \mathrm{C}$ where the healing levels results were similar. This could result from the reduction of the bitumen viscosity with temperature in the presence of the rejuvenator (sunflower oil) as shown in Fig. 9a. In this figure, it can be observed that the viscosity of bitumen (the asphalt binder) considerably decreased with temperature in the presence of oil, except at $-5{ }^{\circ} \mathrm{C}$, which remains almost the same
Fig. 7 Crack-healing results for asphalt samples tested at different temperatures, a without and b with capsules
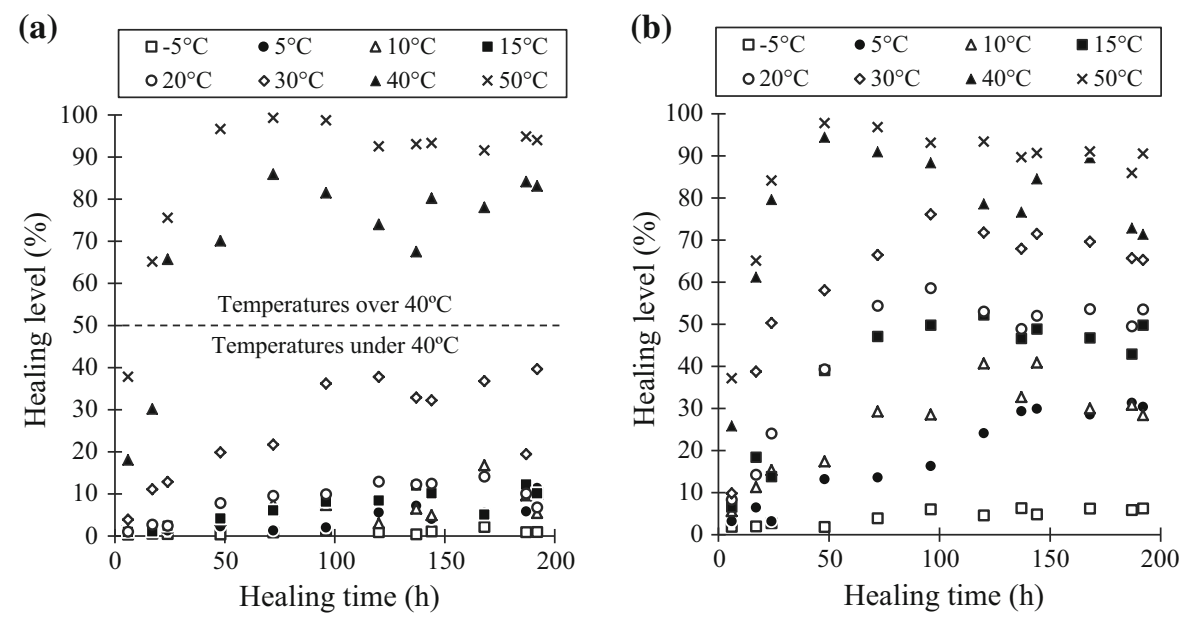


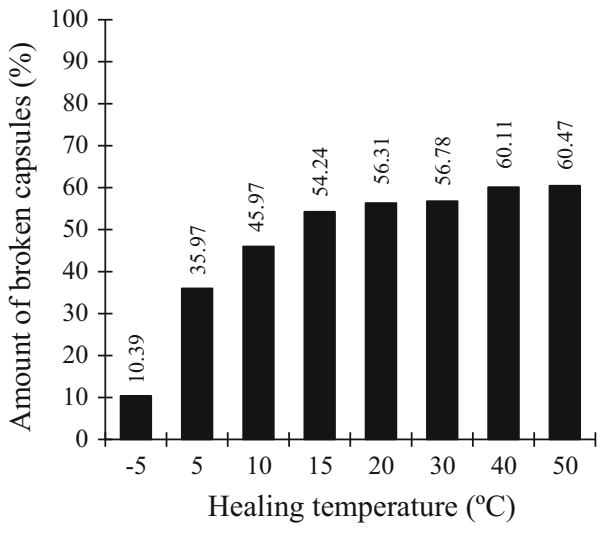

Fig. 8 Amount of broken capsules in asphalt mixtures with $0.5 \%$ capsule content at different temperatures

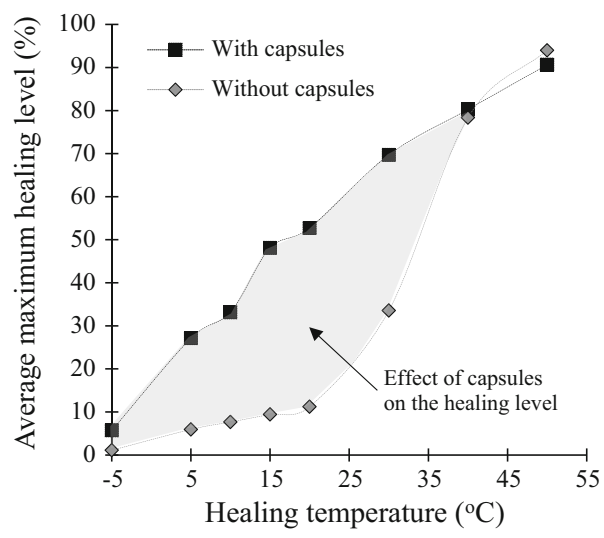

Fig. 10 Average healing levels achieved for asphalt mixture samples with and without capsules at different temperatures
Fig. 9 Oil effect on bitumen and asphalt: a viscosity test for bitumen, and $\mathbf{b}$ thermal expansion for asphalt samples (a)

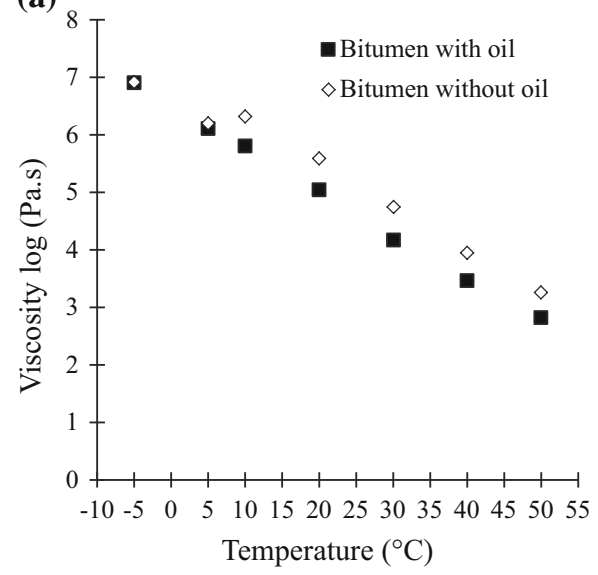

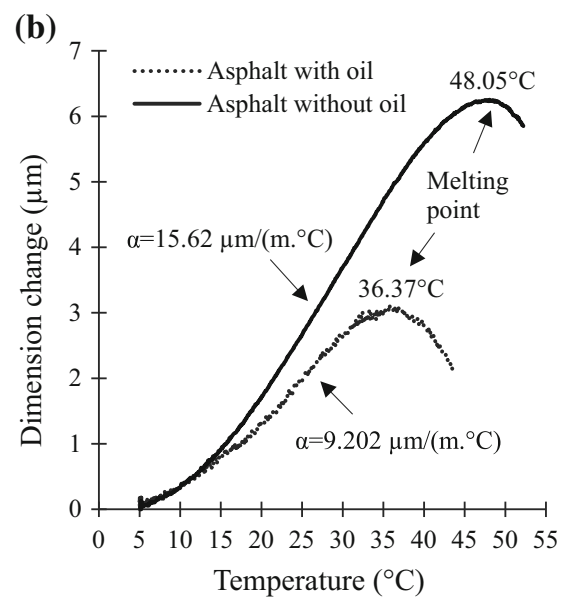

and that explains the lower healing level at this temperature shown in Fig. 7. Likewise, comparing Fig. $7 \mathrm{a}, \mathrm{b}$ it can be seen that for tests at healing temperatures of $40^{\circ} \mathrm{C}$ or higher, the healing level of samples without capsules begin to rise reaching similar or higher values than those of the samples with capsules.

To prove this, Fig. 10 shows the average maximum values of healing levels for the asphalt samples with, and without, capsules versus the different healing temperature evaluated. In Fig. 10, it can be seen that the maximum average healing level for samples with capsules is almost linear with temperature, while there is a jump in the curve of the healing levels for samples without capsules. The curve of samples without capsules is linear until $20{ }^{\circ} \mathrm{C}$, then jumps considerably intersecting the curve of asphalt samples with capsules when it reaches $40{ }^{\circ} \mathrm{C}$, see Fig. 10 . So, the effect of the capsule addition on the healing levels of asphalt is more easily appreciable at temperatures lower than $40{ }^{\circ} \mathrm{C}$.

This result may be due to the combined effect of decreasing viscosity and thermal expansion with temperature, as presented in Fig. 9. In this way, as can be seen in Fig. 9b, for the temperature range evaluated between 5 and $50{ }^{\circ} \mathrm{C}$, the thermal expansion of asphalt mixture samples without oil, $15.62 \mu \mathrm{m} /$ (m. ${ }^{\circ} \mathrm{C}$ ), was higher than that for asphalt mixture samples with oil $9.202 \mu \mathrm{m} /\left(\mathrm{m}\right.$. $\left.{ }^{\circ} \mathrm{C}\right)$, and it continues until reaching the melting point, which is 48.05 and $36.37{ }^{\circ} \mathrm{C}$ for asphalt mixture samples without and with oil, respectively. Therefore, from Figs. 9 and 10 results it can be concluded that: (1) asphalt mixture samples with, and without, capsules present a proportional increase of the healing level when the temperature increases, and (2) there is a relationship between 
the healing level results of asphalt mixture samples with, and without, capsules, which in turn is a function of the variables of viscosity and thermal expansion with the temperature.

\section{Conclusions}

This paper explains the effect of capsule addition and the healing temperature on the self-healing properties of asphalt mixtures. Based on the results, the following conclusions have been obtained:

- The encapsulation procedure presented in this study succeeded in manufacturing self-healing capsules that contain up to $80 \%$ by volume of healing agents, higher than any other capsule of asphalt presented in the literature.

- Mixing temperature did not affect capsules mechanical strength as they can survive mixing and compaction processes during asphalt preparation. Some oil release was noticed but it was about $0.7 \%$ of the total encapsulated oil in the mixture.

- Thermal stability results proved that the capsules suffered only a minor mass loss in the temperature range used for the production of the asphalt mixture, which was caused by the effect of degradation of polymer and water evaporation. The use of other polymer and measure its feasibility for self-healing is recommended for future research.

- The capsule breaking methodology performed in this research was successful to break the capsules under the effect of external loading, releasing their oil to the bitumen. This method could be followed by other researchers for similar tests.

- Capsules show a significant healing levels when added to asphalt samples in comparison to asphalt samples without capsules at healing temperatures equal or less than $30{ }^{\circ} \mathrm{C}$. In addition, the healing level of asphalt samples with, and without capsules increased with the healing time until a maximum value where the healing level remained constant until the end of the test. It is recommended for future research to study the possibility of providing enough rest period on asphalt roads, with respect to rest period that healing start to be constant. Then measuring the self-healing, which might be more economic.
- Healing levels of asphalt samples without capsules start to increase considerably after $30{ }^{\circ} \mathrm{C}$. At $50{ }^{\circ} \mathrm{C}$, the healing levels of asphalt samples without capsules is higher than that with capsules. This explains the effect of viscosity and thermal expansion on self-healing, in the presence of temperature. In this way, it is recommended to study different types of asphalt binder and how their thermal expansion affect self-healing at different temperatures.

- The healing levels for asphalt samples with and without capsules were almost similar at healing temperatures over $40{ }^{\circ} \mathrm{C}$. This indicates that these capsules are not useful for asphalt self-healing at hot climate. For future work using calcium-alginate capsules with oil, the authors recommend that asphalt self-healing tests be performed at healing temperatures below $40{ }^{\circ} \mathrm{C}$, in order to obtain a significant influence of the capsules on selfhealing.

Acknowledgements The first author would like to acknowledge the financial support of the Higher Committee for Education Development in Iraq for his Ph.D. scholarship. The second author wishes to thank the Government of Chile, since this work was partially funded by the CONICYT/BECAS CHILE 74170030. Finally, the authors would like to thank Highways England from the Government of the UK for the funding given, through the Research Project ref. 558065, entitled: Self-healing asphalt using embedded capsules.

Open Access This article is distributed under the terms of the Creative Commons Attribution 4.0 International License (http:// creativecommons.org/licenses/by/4.0/), which permits unrestricted use, distribution, and reproduction in any medium, provided you give appropriate credit to the original author(s) and the source, provide a link to the Creative Commons license, and indicate if changes were made.

\section{References}

1. Wu S, Pang L, Mo L, Qiu J, Zhu G, Xiao Y (2008) UV and thermal aging of pure bitumen-comparison between laboratory simulation and natural exposure aging. Road Mater Pavement Des 9(sup1):103-113

2. Read J, Whiteoak D (2003) The shell bitumen handbook. Thomas Telford, London

3. Burningham S, Stankevich N (2005) Why road maintenance is important and how to get it done. Transport Notes Series; No. TRN 4. World Bank, Washington, DC 
4. Su J-F, Schlangen E, Wang YY (2015) Investigation of the self-healing mechanism of aged bitumen using microcapsules containing rejuvenator. Constr Build Mater 85:49-56

5. Chen X, Dam MA, Ono K, Mal A, Shen H, Nutt SR, Sheran K, Wudl F (2002) A thermally re-mendable cross-linked polymeric material. Science 295(5560):1698-1702

6. Chen X, Wudl F, Mal A, Shen H, Nutt SR (2003) New thermally remendable highly cross-linked polymeric materials. Macromolecules 36(6):1802-1807

7. García Á, Schlangen E, van de Ven M, Liu Q (2009) Electrical conductivity of asphalt mortar containing conductive fibers and fillers. Constr Build Mater 23(10):3175-3181

8. García Á, Schlangen E, van de Ven M, van Vliet D (2011) Induction heating of mastic containing conductive fibers and fillers. Mater Struct 44(2):499-508

9. NL-Agency (2011) Self-healing materials, concept and publications. Publication 3ISHM1001

10. Qiu J, Molenaar AAA, van de Ven M, Wu S, Yu J (2012) Investigation of self healing behaviour of asphalt mixes using beam on elastic foundation setup. Mater Struct 45(5):777-791

11. Bhairampally R, Lytton R, Little D (2000) Numerical and graphical method to assess permanent deformation potential for repeated compressive loading of asphalt mixtures. Transp Res Rec J Transp Res Board 1723:150-158

12. Qiu J (2012) Self healing of asphalt mixtures: towards a better understanding of the mechanism. TU Delft, Delft University of Technology, Delft

13. Apeagyei AK, Grenfell JR, Airey GD (2014) Observation of reversible moisture damage in asphalt mixtures. Constr Build Mater 60:73-80

14. Pauli AT (2014) Chemomechanics of damage accumulation and damage-recovery healing in bituminous asphalt binders. Delft University of Technology, TU Delft

15. Corbett LW (1969) Composition of asphalt based on generic fractionation, using solvent deasphaltening, elution-adsorption chromatography, and densimetric characterization. Anal Chem 41(4):576-579

16. Qiu J (2008) Self healing of asphalt mixes: literature review. TU Delft, Delft University of Technology, Delft

17. García A, Bueno M, Norambuena-Contreras J, Partl MN (2013) Induction healing of dense asphalt concrete. Constr Build Mater 49:1-7

18. Norambuena-Contreras J, Garcia A (2016) Self-healing of asphalt mixture by microwave and induction heating. Mater Des 106:404-414

19. García Á (2012) Self-healing of open cracks in asphalt mastic. Fuel 93:264-272

20. García Á, Schlangen E, van de Ven M, Sierra-Beltran G (2010) Preparation of capsules containing rejuvenators for their use in asphalt concrete. J Hazard Mater 184(1):603-611

21. Chung K, Lee S, Parka M, Yoob P, Honga Y (2015) Preparation and characterization of microcapsule-containing self-healing asphalt. J Ind Eng Chem 29:330-337

22. Su JF, Schlangen E, Qiu J (2013) Design and construction of microcapsules containing rejuvenator for asphalt. Powder Technol 235:563-571

23. Su JF, Wang YY, Han NX, Yang P, Han S (2016) Experimental investigation and mechanism analysis of novel multi-self-healing behaviors of bitumen using microcapsules containing rejuvenator. Constr Build Mater 106:317-329

24. Su JF, Qiu J, Schlangen E (2013) Stability investigation of self-healing microcapsules containing rejuvenator for bitumen. Polym Degrad Stab 98(6):1205-1215

25. García Á, Schlangen E, van de Ven M (2011) Properties of capsules containing rejuvenators for their use in asphalt concrete. Fuel 90(2):583-591

26. Micaelo R, Al-Mansoori T, Garcia A (2016) Study of the mechanical properties and self-healing ability of asphalt mixture containing calcium-alginate capsules. Constr Build Mater 123:734-744

27. Zargar M, Ahmadinia E, Asli H, Karim MR (2012) Investigation of the possibility of using waste cooking oil as a rejuvenating agent for aged bitumen. J Hazard Mater 233:254-258

28. Garcia A, Jelfs J, Austin CJ (2015) Internal asphalt mixture rejuvenation using capsules. Constr Build Mater 101:309-316

29. Mookhoek SD, Fischer HR, van der Zwaag S (2012) Alginate fibres containing discrete liquid filled vacuoles for controlled delivery of healing agents in fibre reinforced composites. Compos Part A Appl Sci Manuf 43(12):2176-2182

30. Ji J, Yao H, Suo Z, You Z, Li H, Xu S, Sun L (2016) Effectiveness of vegetable oils as rejuvenators for aged asphalt binders. J Mater Civ Eng 29(3):D4016003

31. Al-Mansoori T, Micaelo R, Artamendi I, NorambuenaContreras J, Garcia A (2017) Microcapsules for self-healing of asphalt mixture without compromising mechanical performance. Constr Build Mater 155:1091-1100

32. Liang P, Wang H, Chen C, Ge F, Liu D, Li S, Han B, Xiong $X$, Zhao S (2012) The use of fourier transform infrared spectroscopy for quantification of adulteration in virgin walnut oil. J Spectrosc 2013, Article ID: 305604

33. Al-Mansoori T, Norambuena-Contreras J, Micaelo R, Garcia A (2018) Self-healing of asphalt mastic by the action of polymeric capsules containing rejuvenators. Constr Build Mater 161:330-339 